\title{
Afasi og tropologi
}

\section{Indledning til Roman Jakobson: »To aspekter af sproget og to typer afatisk forstyrrelse «}

Når Roman Jakobson (1896-1982) i optakten til sin nu klassiske artikel om »To aspekter af sproget og to typer afatisk forstyrrelse « (1956) skriver, at »Lingvister beskæftiger sig med sproget i alle dets aspekter«, opstiller han et ideal, han selv $\mathbf{i}$ sjelden grad formåede at leve op til. I sin overordentlig store produktion (alene hans udvalgte arbejder, Selected Writings, fylder mere end 5700 store sider) udvikler Jakobson alle lingvistikkens hovedområder (navnlig inden for fonologien var han teoretisk nyskabende), han har behandlet alle den slaviske filologis discipliner, og hans bidrag til studiet af børnesprog, afasi, metrik, poetik, kommunikationsteori og almen semiotik har været af afgørende betydning.

Et vasentligt kendetegn for Jakobsons arbejder - midt i dette vidtspændende interessefelt - er, at selv den mest detaljerede analyse altid i én og samme vending er såvel styret af som udviklende for et overordnet teoretisk synspunkt. Den aktuelle artikel er således andet og mere end et vellykket eksempel på nytten af anvendt lingvistik, for så vidt et metodisk apparat stilles til rådighed for dels en gren af psykopatologien og dels for den litterære stilistik, hvilket Jakobson allerede gør opmærksom på i sin indledning: Eftersom afasiens mest slående symptomer (som oprindeligt skyldes specifikke hjernebeskadigelser) er af sproglig natur, gør de som sådanne krav på en lingvistisk analyse; og omvendt vil en undersøgelse af den gradvise nedbrydning af sprogstrukturen, der kendetegner afasiens forskellige sygdomsformer, bidrage til forståelsen af selve sprogets opbygning.

Jakobson havde allerede erkendt dette forhold for fonemsystemets vedkommende $\mathrm{i}$ en stor afhandling fra 1942, $\gg$ Kindersprache, Aphasie und allgemeine Lautgesetze «, hvor han påviser, at der findes en strengt regelmæssig og - i hvert fald for de her undersøgte sprogs vedkommende - alment gyldig rækkefølge i erhvervelsen af distinkte sproglyd, dvs. i barnesprogets fonetiske tilblivelseshistorie. Under sine førsproglige »pludrekoncerter « udforsker og behersker barnet hele sprogets artikulatoriske register, men ved indgangen til det 
egentlige sprogstadium foretages en streng udvalgelse af først enkle og siden mere komplekse sproglyd (forekomsten af en betydningsintention og en social indstilling er de vaesentligste kriterier herfor, nevner Jakobson). Sammenholdt med afasien er forholdet så dette, at det tidligst erhvervede i barnesproget er det mest resistente i afasien, mens det senest erhvervede er det, der først rammes af den patologiske sprogforstyrrelse (og omvendt igen det, der senest rehabiliteres ved en mulig genoptræning af afatikeren). Jakobson viser senere, hvorledes disse »implikationslove $\ll^{1} \mathrm{~g} \emptyset \mathrm{r}$ sig gældende på alle niveauer i det sproglige hierarki, dvs. ikke alene fonologisk, men også morfologisk og syntaktisk. ${ }^{2}$

Et umiddelbart udgangspunkt for afsnittet om »Sprogets dobbelte karakter« i artiklen nedenfor er kapitlet om »Syntagmatiske og associative forbindelser « i F. de Saussures Cours de linguistique générale (1916), som Jakobson eksplicit henviser til. Saussure elaborerer her sin grundlæeggende dikotomi mellem la langue (sprogformen) og la parole (talen), ${ }^{3}$ idet han siger, at de forhold, der findes mellem lingvistikkens termer, udvikler sig inden for »to distinkte sfærer« svarende til »to former for vor mentale aktivitet, som begge er uundvarlige for sprogets liv «": På den ene side indgår ordene i nogle forbindelser som følge af deres faktiske sammenkiedning i den realiserede diskurs. Disse kombinationer, hvor to eller flere enheder folger efter hinanden i kraft af »udtrykkets lineære karakter« (principperne om tegnets arbitraritet og om udtrykkets linearitet er Saussures to, fundamentale dogmer ${ }^{5}$ ), kaldes for syntagmer ( $\mathrm{fx}$ gen-lase; trods alt; de menneskelige forhold; hvis det er godt vejr, tager vi $i$ skoven osv.), og her făr en given term kun sin betydningsverdi (valeur) i kraft af sin opposition til den forudgående eller efterfølgende term eller til dem begge. På den anden side, uden for diskursen, associeres de ord, der har »et eller andet til færlles«, i hukommelsen, hvor de danner nogle grupper, der holdes sammen af »meget forskelligartede forbindelser «. Ordet undervisning kan således ubevidst, siger Saussure - fremkalde følgende rakker: undervise, underviser, undervist (et bøjningsparadigme); indlaering, uddannelse, instruktion (synonymer); eller indlaring, armering, lokalisering (ord med samme suffiks). Disse anderledes beskafne associative forhindelser, der til forskel fra de syntagmatiske in praesentia forekommer in absentia i en virtuel hukommelsesserie, forestiller Saussure sig lokaliseret i hjernen, hvor de er en del af »dette indre skatkammer «, der udgør sproget hos det enkelte individ. Med en verbal illustration hedder det: »Ud fia dette dobbelte synspunkt kan en sproglig enhed sammenlignes med en bestemt del af en bygning, fx en søjle; denne befinder sig på den ene side $i$ et bestemt forhold til arkitraven, som den understøtter; dette arrangement af to enheder, der begge er til stede i rummet, vekker tanken om den syntagmatiske forbindelse; på den anden side: Hvis 
denne søjle er af dorisk art, fremkalder den den mentale sammenligning med andre stilarter (jonisk, korintisk osv.), som er elementer, der ikke er til stede i rummet: Forbindelsen er associativ. $\ll^{6}$

Det er denne klassiske, strukturelt lingvistiske dikotomi (der er genererende for hele det Saussure'ske begrebskompleks), Jakobson bygger videre på; men til forskel fra Hjelmslev, der radikaliserer den (og dermed iflg. Jakobson ender $i$ et rent »algebraisk « ${ }^{7}$ synspunkt), kan man sige, at Jakobson opbløder den gennem en - bảde i en dagligdags og filosofisk betydning af ordet - mere $»$ realistisk « ${ }^{8}$ approach til det heterogene fæenomen, sproget er, hvilket gør det muligt for ham at inddrage stedse flere af de aspekter, Saussure måtte udelukke, uden at han af den grund behøver at give afkald på nogen analytisk eller teoretisk rigeur. Saussure placerede således de associative forbindelser (med Hjelmslevs siden accepterede udtryk: paradigmet) på en simultanakse og syntagmet på en successionsakse," og når Jakobson i stedet taler om hhv. selektionsakse og kombinationsakse, " markerer han med de mere dynamiske begreber om selektion og kombination, at det sproglige tegn ikke blot skal analyseres som element i en statisk, logisk struktur (koden), men også som genstand for de skiftende ind-og afkodninger, subjekterne uafladeligt foretager, når de kommunikerer indbyrdes - og som hver især involverer såvel selektion som kombination, men i omvendt orden:

Indkoderen starter iflg. Jakobson med en analytisk operation. ${ }^{11}$ Først selekteres fra kodens lager at paradigmatiske muligheder en række størrelser, der i koden befinder sig i et substitutionsforhold og altså er forbundet gennem forskellige grader af lighed eller similaritet ( $\mathrm{fx}$ de enkelte ordklasser eller de enkelte ord i et bøjningsparadigme); herefter foretages en syntetisk operation, idet de selekterede konstituenter kombineres og integreres i en kontekst, hvori de befinder sig i en tilstand af kontiguitet (nærhed). I indkodningen er selektionen således det forudgående, kombinationen det efterfølgende og operationens mål. Afkoderen bliver på sin side fø̆rst konfronteret med de syntetiserede data (kombinationen) og skal herefter analysere dem, dvs. foretage en selektion blandt mulige betydninger (hvilket er mest iøjnefaldende i tilf:elde af homonymi, dvs. hvor et udtryk kan forbindes med flere indhold (jvf. verbalet i Jensen maler kornet), eller i tilfælde af syntaktisk ambiguitet, dvs. hvor en sætning kan forstảs på mere end en måde (jvf. prædikatet i Jensen arbejder på et $s k i b)$ ). I afkodningen er kombinationen det forudgående, selektionen det efterfølgende og målet.

Det er - i Jakobsons lingvistiske perspektiv - først og fremmest disse indog afkodningsprocesser (og med Saussures udtryk samtidig »to former for vor mentale aktivitet «), der i større eller mindre omfang sættes ud af kraft under de afatiske forstyırelser; og i begge af afasiens to hovedformer, den motoriske 
(eller emissive) og den sensoriske (eller receptive), er det i overvejende grad den efterfølgende del af processen (dvs. enten kombinationen eller selektionen), der bliver beskadiget: ${ }^{12}$

\section{INDKODNING AFKODNING}

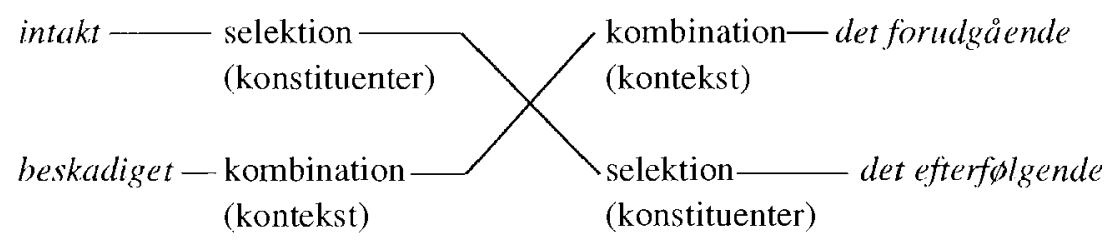

Den motoriske afatiker, hvis selektionsevne er nogenlunde intakt, mens kombinationsevnen er beskadiget (»kontiguitetsforstyrrelse«), kan således nok frembringe en rekke associative serier - jo mere disparate, des større sygdommen er --, men mangler evnen til at indsiette dem i en ordnet, syntaktisk sammenhæng, resulterende i agrammatisme $e^{13}$.

...Yes ... ah ... Monday ... ah ... Dad and Peter Hogan, and Dad ... ah ... Hospital ... and ah ... Wednesday ... Wednesday, nine o'clock and ah Thursday ... ten o'clock ah doctors ... two ... two ... and doctors and $\ldots$ ah ... teeth ... yah. And a doctor ... an girl ... and gums, and I. [Upon questioning about his former employment in a paper mill] Lower Falls ... Maine ... Paper. Four hundred tons a day! And ah ... sulphur machines, and ah ... wood ... Two weeks and eight hours. Eight hours ... no! Twelve hours, fifteen hours ... workin ... workin ... workin! Yes, and ah ...sulphur. Sulphur and ... Ah wood. Ah ... handlin! And ah sick, four years ago.«

Den sensoriske afatiker er heroverfor nok i stand til at foretage en egentlig setningsdannelse, men har alvorlige problemer med at »huske ordene (som mange kender til det fra »dagen derpå《 eller fra især ældre medborgere, der er ramt af forkalkning af hjernens blodkar). Han eller hun lider af »similaritetsforstyrrelse $\ll$ :

»Well, I had trouble with ... oh, almost everything that happened from the ... eh, eh ... Golly, the word I can remenber, you know, is ah ... When I had the ... ah, biggest ... ah ... that I had the trouble with, you know ... that I had the trouble with, and I still have a ... the ah ... different ... The things I want to say ... ah ... The way I say things, but I 
understand mostly things, most of them and what the things are.«

Man kan sammenholde disse mere fyldige eksempler med dem, Jakobson selv anf $\varnothing$ rer i artiklen nedenfor.

Det, der i første række gør Jakobsons artikel om »To aspekter ... « både klassisk og kompleks, er, at det her - via den strukturelle lingvistik - lykkes ham at forbinde analysen af afasiens to hovedformer med en teori om stilistikkens to hovedtroper, metaforen og metonymien, som hermed inddrages under lingvistikkens genstandsområde. Dette er ikke nogen selvfølge. En traditionel lingvist skriver $\mathrm{fx}$ :

»Den kendsgerning, at en vis stjernegruppe på nattehimlen mindede nogle om en tyr, og at en løve på en krigers skjold antyder, at dets bærer er modig, er, forekommer det mig, nonlingvistiske eksempler på den samme trang til analogidannelse, som fungerer i frembringelsen og forståelsen af metaforen. $\ll^{14}$

Man finder imidlertid ikke hos Jakobson den samme, skarpe adskillelse af psykologisk (eller kognitiv) og lingvistisk kompetence, og han viderefører i denne henseende en opfattelse, som allerede Saussure gav udtryk for:

»Psykologisk set, abstraheret fra sit udtryk i ordene, er vor tanke kun en amorf og forskelsløs masse. Filosoffer og lingvister har altid varet enige om at anerkende, at uden tegnenes hjælp ville vi være ude af stand til at skelne mellem to ideer på en klar og konstant måde. Taget i sig selv er tanken som en tåge, hvor intet er nødvendigt afgrænset. Der findes ingen præetablerede ideer, og intet er distinkt før sprogets tilsynek omst. $\ll^{15}$

Mht. metaforen og metonymien bemierker man, at Jakobson ikke - som den klassiske retorik og den heraf udviklede stilistik - analyserer disse to troper som isolerede figurer blandt andre inden for et stort inventarium, men som to fundamentale og indbyrdes forbundne processer $i$ sproget. Man bemærker desuden, at de to grundbegreber, Jakobson bringer i anvendelse i denne sammenhæng, begreberne om similaritet og kontiguitet, hver især appliceres på begge af sprogets »akser«. På selektionsaksen er elementerne »normalt« kategoriseret ud fra varierende grader af similaritet (Jakobson taler også mere generelt om akvivalens), men hos afatiske patienter med $\gg$ similaritetsforstyrrelse er den semantiske gruppering overvejende styret af spatial eller temporel kontiguitet (jvf. den kvindelige patient, der i artiklen nedenfor forklarer cn bestemt gruppering af ting med henvisning til et »udstillingsvindue «, hvor 
»det ikke betyder noget, hvad tingene er«, dvs. hvor de ikke behøver at ligne hinanden). Pả kombinationsaksen er elementerne forbundet gennem kontiguitet, men Jakobson taler her også om positionel similaritet mellem elementer,der kan stå på samme plads i syntagmet (man kan her eksemplarisk tanke på P. Diderichsens $\gg s æ t$ tningsskema $<,{ }^{16}$ der precist angiver de enkelte sætningsleds mulige positioner på dansk). Begge de to grundbegreber, similaritet og kontiguitet, rummer altså både et »formelt « (syntaktisk) og et »substantielt « (semantisk) aspekt. Det er »similaritetsforstyırelsen«, der mest oplagt peger på de semantiske grupperinger, baseret på kontiguitet. Metonymien som sådan vidner om deres permanente tilstedevarelse - og den gør det måske også umiddelbart lettere at se, at de to fundamentale processer, Jakobson opererer med, selektion og kombination, er indbyrdes forbundne i den sproglige kreativitet. Selv om metonymien i første omgang ses som et produkt af kombinationsevnen, er den - i den realiserede diskurs - lige så vel som metaforen resultatet af en selektion fra et paradigme, der blot er anderledes konstrueret end det, der etablerer metaforen. Med en helt traditionel formulering: Metonymien er, ligesom de $\emptyset v r i g e$ troper, en paradigmatisk »afvigelse «, idet et tegn ( $\mathrm{x}$ en »perser «) er selekteret $\mathrm{i}$ stedet for et andet (en »kat« eller et »tæppe«), som det er relateret til gennem en bestemt type nxerhedsforbindelse. ${ }^{17}$

I sine afsluttende overvejelser $\mathrm{i}$ artiklen nedenfor giver Jakobson en interessant fork laring på, hvorfor litteraturen om metaforen - efter hans opfattelse åbenbart med urette - er så uligt større end den, der er blevet metonymien til del (der er næppe nogen sinde skrevet en monografi om metonymien). Det er lettere, hævder han, at etablere et metasprog med metaforen som objekt. Symbolerne i et metasprog er forbundet med symbolerne i det sprog, der refereres til, gennem similaritet - ligesom den metaforiske term med den term, den er substitueret for. Metasproget er derfor mere homogent i forhold til det metaforiske sprog, hvorimod metonymien er baseret på et andet princip og derfor lettere trodser fortolkning. ${ }^{18}$ Metaforen har i øvrigt, siger Jakobson, større affinitet til poesieu (navnlig den romantiske og symbolistiske, anføres det) og dermed til sprogets poetiske funktion (dvs. fokuseringen på selve meddelelsen som sådan, for dens egen skyld), mens metonymien er nærmere forbundet med prosaen (med »realismen« inden for litteraturen eller med den »pragmatiske prosa « slet og ret) og følgelig med sprogets referentielle ${ }^{19}$ funk tion.

Nu kan man umiddelbart indvende, at poesien netop har sine perioder, og at metonymien (samt synekdoken, som Jakobson slår sammen med metonymien) er righoldigt repræsenteret i fx klassicismens vers. ${ }^{20}$ Man kan også indvende, at metonymien i selve sin formelle struktur (dvs. som selektion af en alternativ term) adlyder samme princip som metaforen (hvilket definerer dem begge som troper). 
Til gengæld adskiller de sig så - »substantielt«, om man vil - mht. den referentielle funktion. Mens metaforen umiddelbart etablerer et brud $\mathrm{i}$ forhold til det »sadvanligvis« betegnede objekt (designatum, som man vanskeligt undgår at inddrage i semantikken), bliver metonymien til ved en forskydning i forhold til dette. Når Pascal - som semantikeren M. le Guern citerer - fx skriver: »Le noud de notre condition prend ses replis et ses tours dans cet abîme', ${ }^{21}$ betyder »abîme « ikke »afgrund « i konkret forstand, men - i Pascals religiøse kontekst - snarere »mysterium«. Anderledes udtrykt: Metaforen opererer ud fra et brud med tekstens semantiske isotopi.22 Heroverfor betegner metonymien en forskydning - en glidning i forhold til referenten, men inden for én og samme isotopi, som nål Zola fx skriver, at »nogle grove stemmer skændtes i korridorerne « eller »Der var en forvirring, et virvar af hoveder og arme som bevægede sig voldsomt, nogle var ved at sætte sig ned og gøre sig det bekvemt, andre blev stiedigt stående for at kaste et sidste blik omkring sig. $\ll^{23}$ Det er denne referentielle forskydning, der får J. Lacan til - ud fra en kort henvisning til Freud i Jakobsons tekst nedenfor - at identificere metonymien med den primærproces, psykoanalysen netop beskriver som forskydning, ${ }^{24}$ mens det er mere uklart, hvorfor psykoanalysens fortutning - med Lacans parallelisme skulle være en metafor. For så vidt fortætningen iflg. Freud betegner den kendsgerning, at ét element i den manifeste drøm leder frem til flere ubevidste indhold, kan den udmerket analyseres som en pars pro toto - altsi̊ en synekdoke, som Jakobson siger. 25

Under alle omstandigheder skal man fastholde det alment semiotiske - og strukturelle - perspektiv hos Jakobson. Metafor og metonymi kan dybest set ikke analyseres uafhængigt af hinanden: de repræenterer to fundamentale processer i sproget og i vor mentale aktivitet, og de indgår begge - med forskellig hierarkisk vægt i enhver betydningsdannelse. I artiklen nedenfor er det umiddelbart de afatiske forstyrrelser, der giver anledning til refleksionen. Man bliver ofte først opmærksom på det normale, når det går galt.

\section{Noter}

1. En mere almen formel herfor findes in R. Jakobson \& M. Halle: »Phonology and Phonetics «, in samme: Fundamentals of Language, Haag/Paris 1956, p. 38.

2. Jvf. artiklen nedenfor samt R. Jakobson: »Aphasia as a Linguistic Topic « (org. 1955), in: Selected Writings (Paris/Haag 1971 ff, herefter forkortet $S W$ ) II, pp. 229-238; samme: »Toward a Linguistic Classification of Aphasic Impairments « (org. 1963), in: $S W$ II, pp. 289-306; samme: »Linguistic Types of Aphasiak (org. 1966), in: $S W \Pi$ I, pp. 307-333; og samme: $\gg$ On Aphasic Disorders from a Linguistic Angle« (org. 1980), in: SW VIII, PP. 128-140. 
3. Nogle centrale passager fra Saussures Cours er oversat til dansk under titlen »Lingvistikkens objekt in: P. Madsen (red.): Strukturalisme. København 1970.

4. Jvf. F. de Saussure: Cours de linguistique générale, Paris 1916, p. 170; SJ fremhaver.

5. Jvf. Saussure op.cit., pp. 100-103; da. overs. pp. 35-39. Jakobson kritiserer begge principper på en overbevisende måde i Jakobson: »På sporet af sprogets vasen « (org. 1966) in: Elementer, funktioner og strukturer $i$ sproget, København 1979, pp. 89-102.

6. Jvf. Saussure op.cit., p. 170.

7. Jvf. Jakobson \& Halle: Fundamental's of Language, pp. 26-28.

8. Jvf. Jakobson: »Tegn og sprogsystem« (org. 1962), in: Jakobson: Elementer, funktioner og strukturer $i$ sproget, p. 86.

9. Jvf. Saussure op.cit., pp. 114-117; da. overs. pp. 39-41.

10. Ordet »akse« anvendes ikke $\mathrm{i} »$ To aspekter ...«, men in: Jakobson: »Closing Statement: Linguistics and Poetics «, in: T.A. Sebeok (ed.): Style in Language, Cambridge, Mass. 1960. Da. overs. (med udeladelser): »Poetik og lingvistik in: Vindrosen nr. 7, København 1967.

11. Jvf. Jakobson; »Toward a Linguistic Classification ...«,in: SW II, pp. 289-306.

12. Jvf. ibid., p. 296. Opstillingen her er let modificeret $i$ forhold hertil.

13. Eksemplerne stammer fra H. Goodglass: »Studies on the Grammar of Aphasics«, in: H. Goodglass \&. S. Blumstein (eds.): Psycholinguistics and Aphasia, Baltimore \& London 1973, pp. 185 \& 186.

14. Jvf. J.M. Sadock: »Figurative Speech and Linguistics«, in: A. Ortony (ed.): Metaphor and Thought, Cambridge 1979, p. 46.

15. Jvf. Saussure op.cit., p. 155.

16. Jvf. B. Diderichsen: Elementer Dansk Grammatik, København 1946, pp. 184-201.

17. Mhp. konkrete eksempler pă metonymien i dens forskellige former må jeg her henvise til traditionelle fremstillinger som fx U. Albeck: Dansk Stilistik, København 1939 eller, som den måske mest udtørlige nogensinde P. Fontanier: Mamuel classique pour l'étude des tropes ou Élements de la science du sens des mots (org. 1821), in: P. Fontanier: Les figures du discours, Paris 1977.

18. Jvf. artiklen nedenfor og i øvrigt Jakobson: »Metalanguage as a Linguistic Problem (org. 1976), in: SW VII, pp. 113-121.

19. Jakobsons liere om sprogets emotive, konative, referentielle, poetiske, fatiske og metasproglige funktioner er bedst beskrevet in: Jakobson: »Poetik og lingvistik« (se note 10 ).

20. Jvf. Fontanier op.cit., pp. 79-97.

21. »Knuden i vore livsbetingelser făr sine bugtninger og snoninger i denne afgrund.« Jvf. M. le Guern: Sémantique de la métaphore et de la métonymie, Paris 1973, p.15.

22. Jvf. A.J. Greimas: Sémantique structurale, Paris 1966, p. 96. Da. overs. Strukturel semantik. København 1974, p. 166.

23. Jvf. le Guenn op.cit., pp. 14 \& 15; SJ fremhaver.

24. Jvf. J. Lacan: »L'instance de la lettre dans l'inconscient ou la raison depuis Freud « (org.1957). Da. overs. »Bogstavets instans i det ubevidste in: J. Lacan: Det ubevidste sprog. København 1973.

25. En artikel, der bl.a. uddyber disse forhold, er inder forberedelse til publikation juni 1995. 